\title{
Electrochemical Fabrication of Silver Dendrites as an Excellent Platform for Surface Enhanced Raman Scattering Application
}

\author{
Chao $\mathrm{Li}^{1}$, Ruihui Dai ${ }^{2}$, Xiaojia $\mathrm{Wu}^{3}$, Ruifang $Q i^{2}$ and Jingjun $\mathrm{Ma}^{3, *}$ \\ ${ }^{1}$ College of Sciences, Agricultural University of Hebei, Baoding 071001, P.R. China \\ ${ }^{2}$ Department of Basic Courses, Agricultural University of Hebei, Huanghua 061100, P.R. China \\ ${ }^{3}$ College of Science and Technology, Agricultural University of Hebei, Huanghua 061100, P.R. China \\ *E-mail: jingjunma_hebeiag@foxmail.com
}

doi: $10.20964 / 2017.04 .44$

Received: 1 January 2017 / Accepted: 19 February 2017 / Published: 12 March 2017

\begin{abstract}
The synthesis of silver dendritic framework can be achieved by scattering graphene oxide (GO) into the solution of $\mathrm{AgNO}_{3}$. This convenient electrochemical method with single stage involved was issued in the work. A clear-cut dendritic framework of the silver object generated by such synthesis was shown by means of scanning electron microscopy. What is more, the observation of X-ray Diffraction revealed the cubic phase of the silver. GO's existence was indicated in silver dendrites by way of UVVis spectroscopy, in which GO went through electrochemical reduction as the silver was deposited. With the existence of $\mathrm{GO}$ and $\mathrm{AgNO}_{3}$, this research assessed the SERS approach's improvement as well as analysis capacity demonstrated in the measurement of canola oil and $\alpha$-tocopherol. In addition, the work researched into the practicability of adopting such SERS approach to analysing canola oil' oxidation. The results revealed that SERS was highly sensitive in the analysis of dilute canola oil and $\alpha$-tocopherol, and that in a mixture it was possible to analyse such constituents above at the same time.
\end{abstract}

Keywords: Electrodeposition; Silver dendrites; Graphene oxide; SERS; Canola oil; $\alpha$-tocopherol

\section{FULL TEXT}

(C) 2017 The Authors. Published by ESG (www.electrochemsci.org). This article is an open access article distributed under the terms and conditions of the Creative Commons Attribution license (http://creativecommons.org/licenses/by/4.0/). 